\title{
THE INTERPELVI-ABDOMINAL AMPUTATION 283
}

\section{THE INTERPELVI-ABDOMINAL AMPUTATION.}

\author{
WITH NOTES ON TWO CASES.
}

\section{By J. hogaRth PRINGLe, Grasgow}

IN the Lancet of Feb. 20, 1909, I published a short paper on the interpelv1abdominal amputation, in which I recorded the histories of three patients for whom I had carried out the operation, and gave a list of the cases $I$ had been able to find up to that time. These numbered $21 \mathrm{ln}$ all, 18 being cases of sarcoma, and 3 of tuberculous disease of the hip-bone. My own experiencc concerned two patients with widespread tuberculous disease, and one whth sarcoma, and I may here give brief abstracts of these cases.

Case 1.-A girl, age 10, was first seen in November, 1899, suffering from tuberculous disease of the left hip-joint. The joint was excised, and the wound became tuberculous. About the end of February, 1900, a large abscess formed in the iliac fossa. On March 5 exarticulation at the hip-joint, with removal of the acetabulum and a considerable part of the ilium, was done, a large fotid abscess being opened into. On June 1 the left os coxæ was removed. The patient lived for fourteen years afterwards, and died of some cerebral condition the nature of which is not known to me possibly it was tuberculous in origin.

Case 2.-Adult male, admitted in May, 1902, with abscess over left Poupart's ligament, which was opened and healed well. Re-admitted in 1904 with a large left gluteal abscess, which healed well after incision. Re-admitted in 1906 with the left hip-joint flexed and fixed at a right angle, there were sinuses at the sites of the former incisions, and the patient was very emaciated. In May, 1906, exarticulation at the left hip-joint, the acetabulum was bored through and a large intrapelvic abscess opened, and a large part of the ilium was removed above and behind the acetabulum for free dramage. The wound never healed, and in October, 1906, the left os coxæ was removed. Death took place from shock about fourteen hours later.

Case 3.-Male, age 18, first seen in November, 1906, with a sarcoma of the llower extremity of the left femur. The limb was amputated below the trochanters. In February, 1908, there was a small tumour at the origins of the left hamstring muscles, and on Feb. 12 the interpelvi-abdominal amputation was carried out. Death occurred on July 3 , with metastases in various parts of the body

Of the 19 cases of sarcoma known up to that date, only 6 patients survived the shock of the operation, and 13 died, a mortality of 68.4 per cent. Of the 5 cases of tuberculous disease, 2 recovered-a patient of Bardenheuer and one of my own.

Since my former paper there have been $\mathbf{1 7}$ additional instances of the operation recorded 9 for neoplasms, 7 for tubercle, and 1 for acute osteomyelitıs. Last year 2 patients were operated upon successfully by me, and it may be worth while to review the subject again. 


\section{THE BRITISH JOURNAL OF SURGERY}

The indications for the operation are -

1. Neoplasms arising from (a) The hip-bone, (b) The femur so high up that the disease cannot be removed by an exarticulation at the hip-joint, (c) Muscles or fasciæ in the region of the hip.

2. Infective processes involving the hip-bone (a) Tuberculous disease, (b) Acute osteomyelitis, (c) Actinomycosıs might possibly justıfy the operation in some rare instances.

In the majority of the cases the operation has bcen carried out in one stagenamely, removal of the limb along with the hip-bone, but in a few it has been done in two stages-exarticulation at the hip-joint, followed by the removal of the hip-bone at a later date. This point is of some importance with regard to the cases of unfective disease which may require the operation, and the factors which, in my opinion, should determine which of these procedures is the correct one to follow in the case of tuberculous disease are (1) The extent of the disease, and (2) The state of the patient at the time of operation.

In my own experience of advanced tuberculous disease of the pelvis with intrapelvic suppuration, I have found that exarticulation at the hip-joint along with removal of the acetabulum and the adjacent part of the iliac bone has sometimes given very satisfactory results. This had been carried out in my two patients for whom it eventually became necessary to remove the hipbone, and although in itself it is an operation of considerable severity, it is decidedly less severe than a primary interpelvi-abdominal amputation in one sitting.

An important fact to be kept in mind is that. after the interpelviabdominal amputation, any support for an artificial limb is removed, only a soft elastic surface is left, as yielding as the anterior abdominal wall of any ordinary individual , so that on this account every endeavour should be made to preserve the hip-bone. In Case 1, where the patient survived her operation, a very large re-formation of bone took place in the stump, to outward appearances it closely resembled one after an exarticulation at the hup, and she could have worn an artificial limb as well as any patient can after that operation, but I never felt justıfied in advising her to go to the expense of getting one. Axhausen, in the hope of giving a support for an artificial limb, grafted a plece of the patient's tibia between the sawn ends of the bone. but unfortunately his patient (see Table, No. 27) died mine hours after the operation, this is the only instance known to me of any attempt of this nature having been made.

When a patient has undergone the serious ordeal of exarticulation, the removal of the hip-bonc by a second operation, should it be dcemed advisable, makes a big demand on his vitality and powers of resistance. My second patient died from shock directly due to this, and any operation which may be a possible direct cause of death is one which ought to give us pause to consider whether we should urge it upon a patient.

Morestin operated in 1902 upon a female patient suffering from sarcoma of the pelvis, the operation was carried out in one stage, and the patient (No. 18) died. In the following year he spoke of it as a 'meurtrière operation,' and suggested that a modification, which he termed the 'intra-iliac' amputation, 
might replace the interpelvi-abdominal operation, and especially for those cases of tuberculous disease which require extensive removal of the hip-bone. He has since reported two cases in which he carried out this operation, both of them being done in two stages, the first patient recovered, and the second died (Nos. 38 and 40).

In this intra-iliac operation Morestin divides the ilium vertically downwards into' the sciatic foramen, the horizontal pubic ramus inside the iliopectineal eminence, and the ischium horizontally at the level of the great sciatic foramen, in this manner he preserves the body of the pubis and the tuberosity of the ischium, attached to each other by their rami, and in describing the state of his first patient after the operation, he wrote. "the patient can sit and the tuberosity gives him firm support." In his description of the operation, however, he draws attention to the great amounc of hæmorrhage owing to the cicatricial state of the tissues which results from the long-continued suppuration and the previous exarticulation, and it does not appear from his writings that this intra-iliac amputation is any less severe than a complete removal of one hip-bone. In Cases 1 and 2 of mine, the pubic ramus fractured before the pubic body had been separated from the bone of the opposite side, and the fractured surface of the bone was definitely tuberculous, this would have been left behind had Morestin's modified operation been carried out. My own inclination is towards a complete removal of the hip-bone in these cases.

I believe there is more justification for the operation in one sitting in what must be the extremely rare cases of acute osteomyelitss of the os coxæ that require removal of the entire bone, although I confess to difficulty in understanding how, in a case of this nature, the operation can be called for. Personally $I$ have only met with two cases of this disease, and in each it was limited to the ilium, as it usually appears to be, and pus had formed on both surfaces of the bone, as it probably does in all these cases, owing to the comparative thmness of the bone and its cancellous structure. After the removal of practically the whole of the ilium except its acetabular portion, these two patients recovered.

In a case where there was virulent infection on the pelvic aspect of the hip-bone, such as would occur in an acute osteomyelitis, one would hardly expect a patient to be in satisfactory condition for the second operation after a preliminary amputation at the hip-joint. Even in old-standing cases, where the acute stage has been passed, to do the operation in two stages hardly seems the correct procedure, as the bone primarily involved is not removed until the second operation, and the removal of the os coxæ alone is hardly less troublesome than removal of this bone along with the limb, so that the gain in this respect is practically nil. I gather, from the very short quotation of Gaudier's case, "ostéomyélite aıguë coxofémorale, lésıons suppuratıves étendues ayant necessité la désartıculatıon interilio-abdomınale en deux temps principaux," in the Zentralblatt für Chrrurgıe, 1914, p. 360, that the operation was carried through in two stages, but the reasons for this, and the length of time that elapsed between the development of symptoms and the carrying out of the operations, are not stated.

With regard to neoplasms, the question of operating in two stages can 
only rarely arise. Up to the present time there are only two cases recorded in which the operation has been done in this manner, and both were done for recurrence of sarcoma in the hip-bone or its muscles-(1) After exarticulation at the hip, as in one of Girard's cases (No. 7), and (2) Following an amputation through the shaft of the femur, as in my own case (No. 23). All the neoplasms that have bitherto required this operation have been sarcomata.

Primary sarcoma of the hip-bone almost invariably grows from the ilium, and in cases that are met with at an early stage it may be possible to remove the disease by operations less mutilating in their effect than is the interpelvi-abdominal amputation. I have twice removed the ilium for sarcoma, leaving the acetabular portion. Where the disease is too far advanced for this, a resection of one entire hip-bone, with or without resection of the head of the femur, may be carried out, and the lower limb preserved in a comparatively functional condition. This has, I believe, been done 9 times altogether, with 5 deaths $(55.5$ per cent) and 4 recoveries.

Where the disease is still further advanced, and in those cases where the neoplasm rises from the upper extremity of the femur or its muscles, the interpelvi-abdominal amputation is the only resource we have to fall back upon, and in these cases it must always be a removal of the limb along with the hip-bone at one sitting.

All the cases of this operation that I can find recorded are included in the list on opposite page. In this list I include the case in which Faure began but did not complete the operation, for it is highly to be desired that all the fatal cases should be known.

The most serious point to be considered with regard to the operation is the question of shock. The amputation entails the greatest mutilation for which surgery is responsible, the wound made is a very large one, and the effect upon the vitality of the patient must always be extremely severe. For this reason I classify the four cases recorded by Nanu (No. 12), Orlow (No. 17), Ransohoff (No. 25), and Krynski (No. 28) as 'surviving', for although death took place in Nanu's patient on the twentieth day (from sepsis following upon gangrene of the posterior flap), in Orlow's and Krynski's cases on the thirty-fifth day (from sepsis and cachexia respectively), and in Ransohoff's patient on the thirty-eighth day (from sepsis), the four patients survived the immediate effects of the operation.

Freeman, according to his own drawing published in Keen and Da Costa's paper, only removed about one half of the ilium and sschum along with the pubic part of the bone, he sawed through the acetabulum. But the casc ought, I think, to be included in this category, as also should Morestin's two cases (Nos. 38 and 40) of the intra-iliac operation. Freeman's patient died twenty months after the operation with metastasis in the abdominal wall (Ransohoff).

During 1915 two patients came under my care upon whom it was considered advisable to carry out the operation. The chief points in their clinical histories are as follows -

Case 4.-F McI., age 34, a barber, was admitted on July 9 , 1915, to the Royal Infirmary, Glasgow, suffering from a large tumour of the right femur of at least 
TABLE OF INTERPELVI-ABDOMINAL AMPUTATIONS.

\begin{tabular}{l|l|l|l|l}
\hline No. & Date & Operator & Result & MrPerence \\
\hline
\end{tabular}

\section{Cases of Sarcoma.}

\begin{tabular}{r|r|l}
1 & 1889 & Billroth \\
2 & 1894 & Jaboulay \\
3 & 1894 & Cacciopoli \\
4 & 1895 & Jaboulay \\
5 & 1895 & Jaboulay \\
6 & 1895 & Gayet \\
7 & 1895 & Girard (in 2 stages) \\
8 & 1898 & Girard \\
9 & 1898 & Kocher \\
10 & 1899 & Faure \\
11 & 1899 & Freeman \\
12 & 1900 & Nanu \\
13 & 1900 & Salistcheff \\
14 & 1900 & Kadjan \\
15 & 1901 & Savariaud \\
16 & 1901 & Gallet \\
17 & 1901 & Orlow \\
18 & 1902 & Morestin \\
& & \\
19 & 1902 & De Ruyter \\
20 & 1903 & Keen and Da Costa \\
21 & 1904 & Kocher \\
22 & 1907 & Lastaria \\
23 & 1908 & Pringle (in 2 stages) \\
24 & 1909 & Bier \\
25 & 1909 & Ransohoff \\
26 & 1909 & Pagenstecher \\
27 & 1909 & Axhausen \\
28 & 1909 & Krynsk \\
& &
\end{tabular}

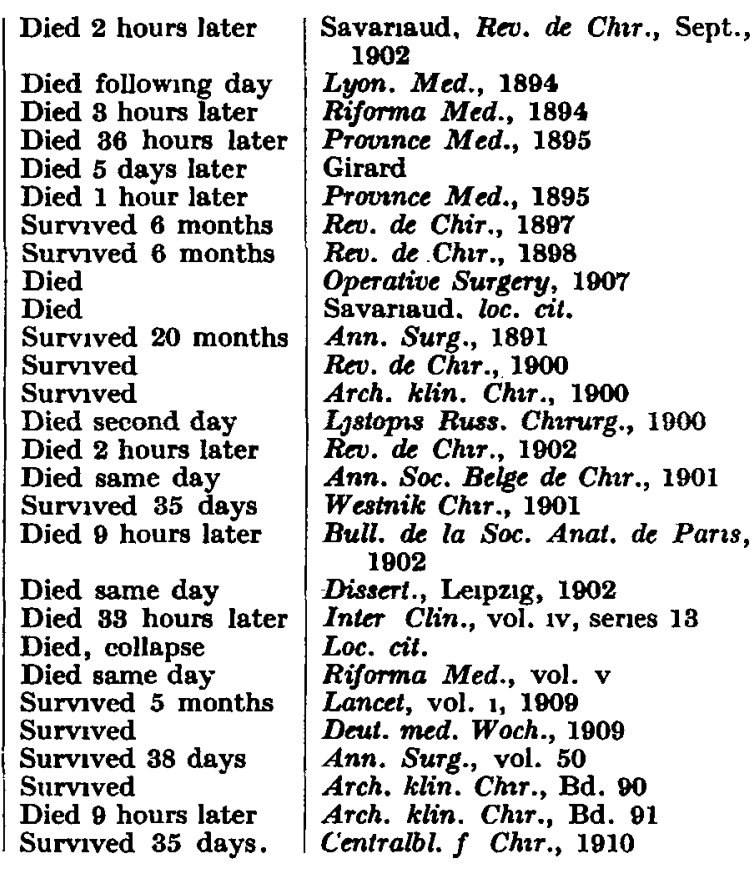

Cases of Tuberculous Disease of Pelvis.

\begin{tabular}{l|l|l|}
29 & 1895 & Girard \\
30 & 1897 & Bardenheuer \\
31 & 1900 & Gallet \\
32 & 1900 & Pringle (in 2 stages) \\
33 & 1902 & Ribera (Simon) \\
34 & 1902 & Ribera \\
35 & 1902 & Ribera \\
36 & 1903 & Christel (Dreist) \\
37 & 1905 & Verneuil \\
38 & 1905 & Morestin (in 2 stages) \\
39 & 1906 & Pringle (in 2 stages) \\
40 & 1909 & Morestin (in 2 stages)
\end{tabular}

Died same day
Survived
Died 6 hours later
Survived 14 years.
Died, collapse
Died eighth day
Died, collapse
Survived
Died 2 hours later
Survived
Died 14 hours later
Died 5 hours later

Rev. de Chrr., 1898

Verh. Deut. Gesel. f. Chir., 1897

Jout de Chrr., 1901

Lancet, vol. 1, 1900

Siglio Med., 1803

Siglio Med.. 1808

Siglio Med., 1908

Deuts. Zeits. $f$ Ch., Bd. 71

Jour Chir Belge., vol. v, 1905

Bull. Soc. Chir Parzs, vol. Xxxiv

Lancet, vol. 1, 1909

Bull. Soc. Anat. Parks, vol. 1xxxıv

Case of Acute Osteomyelitis.

41 | 1913 | Gaudier (in 2 stages) | Survived

| Bull. Soc. Chir Parzs, 1913, n.s.

In the Index Medicus for 1910 there is a reference to a case operated by Sinakevich, and reported in Khirurgia Mosk for 1910, "Excision of entire lower extremity together with pelvis." No further details accessible. 
ten months' duration. When he first observed it, it was about the size of his fist, and situated in the lower part of Scarpa's triangle. He has only had pain within the last few weeks, and chiefly after walking or standing. For the past month or more he has had difficulty in putting on his socks and boots, as he cannot flex his right hip-joint owing to the bulk of the tumour.

He contracted syphilis sixteen years prevously, and took mercury for three

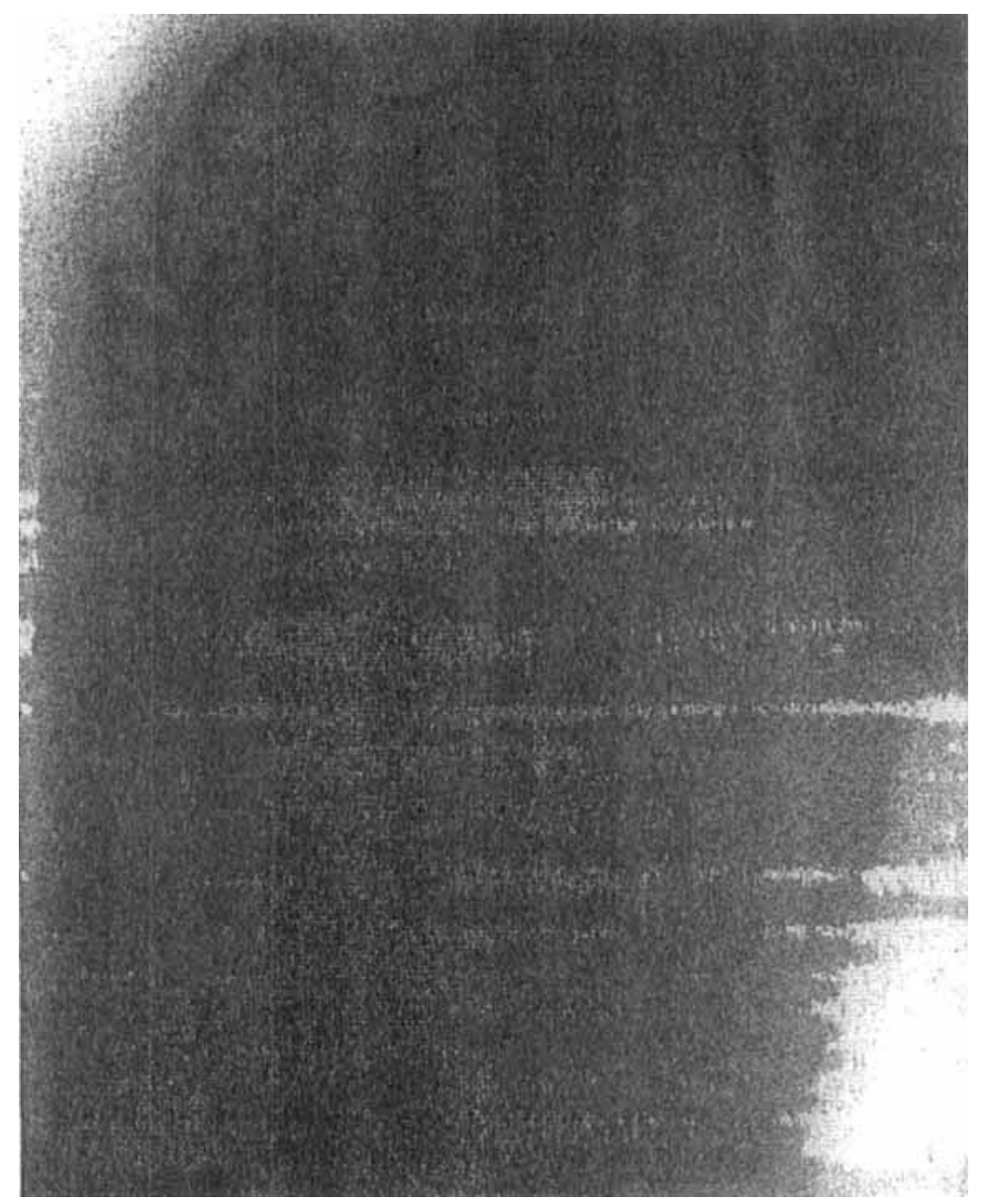

Fra. 191.-Case 4. Sklagram ahowng tumour of the neck and upper thurd of the fernur, and its relation to the hip-bone.

years. The Wassermann reaction is positive. He admitted being a hard drinker and smoker.

There is a very large tumour occupying the upper two-thirds of the right thigh, causing a very marked prominence antenorly as well as at the sides of the thigh, it reaches up to Poupart's ligament, filling Scarpa's triangle. Firm in consistence, on the whole, but elastic in parts and somewhat nodulated in outline, it can be felt reaching almost to the summit of the great trochanter outside, and on the inside up to the ramus of the ischium. Flexion, adduction. and internal rotation at the 


\section{THE INTERPELVI-ABDOMINAL AMPUTATION}

hip-joint are practically abolished. The skin over the tumour is normal in appearance. He suffers from a widespread psoriasis.

The skuagram (Fig. 191) shows the relations of the tumour to the hip-bone and femur. It was considered to be a chondrosarcoma. The patient's internal organs were normal, and no evidence of growth into the pelvic cavity could be obtained.

July 24.--The interpelon-abdominal amputation was done (vide infra):

The appearance presented by section of the femur and the tumour is shown in Fig. 192. The twmour grew from the neck and upper thard of the femur, the tissue of which was almost completely replaced by it. In the main the tumour appeared to be cartilaginous, but there were a few cystic spaces in it.

The patient made an excellent recovery. He suffered very little from shock. The stovane along with the scopolamine and morphine acted well, and he only had a small quantity of ether during the early stages of the operation. He went out of the hospital well (Fig. 198).

Case 5.-Mrs. H., age 46, was admitted to the Royal Infirmary on July 27 , 1915, with a large tumour in the right thigh. She first noticed the swelling about twelve months before, but pard little attention to it until it began to enlarge more rapidly in January, 1915, and to cause pain. On July 17, without making any special effort, she expenenced severe pain in the thigh, and since then has not been able to walk or even to move the limb, and has been confined to bed in consequence. During the last ten days the tumour has increased in sıze rapıdly

She is much emaciated, and often vomits after food, after admission she was only able to take the lightest food without vomiting.

The right thigh is occupred by a large tumour, the prominence of which begins immediately below the anterior superior spine, and extends rather more than half way down the thigh. The skin of the thigh is dusky red in colour, large veins stand out prominently all over it, and in the sacral region the skin has the appearance as if it were about to slough.

The patient can only lie upon her nght side, and is unable to move the right limb at all; any attempt to move it causes great pain. The tumour has an elastic feeling all over, and nowhere is it fluctuant. It extends well up into the gluteal region behind the trochanter, as well as into the adductor muscles at their origins

voL. IV -NO. 14. 
(Fig. 195-which, however, does not show the real extent of the growth as found on palpation).

The internal organs were all normal, and no pelvic extension could be discovered.

On Aug. 3, 1915, the complete interpelvi-abdominal amputation was done. The patient, having had scopolamine and morphine one hour before, had a spinal

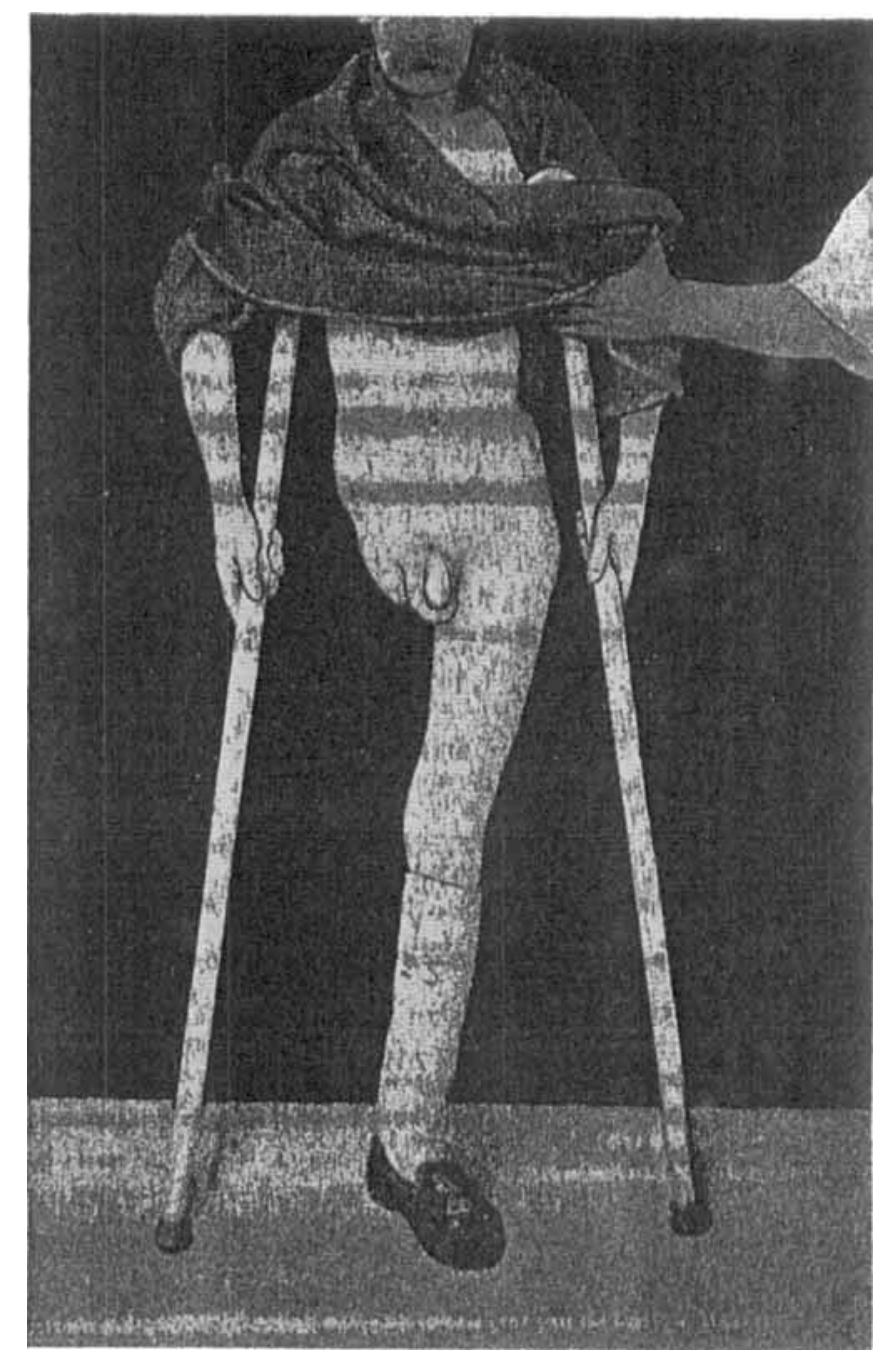

Fie. 193.-Case 4. The pationt after interpelv1-abdominal amputation of the right limb.

injection of stovaine after being brought to the theatre, and had no general anæsthetic at all. She exhibited a certain degree of shock after the operation, much more than did the man, but got over it farrly quickly. She was greatly troubled with vomiting, for several days following, which caused some anxiety, but after this was got over she made a first-rate recovery.

She went out from hospital on Sept. 18, very well. 


\section{THE INTERPELVI-ABDOMINAL AMPUTATION 291}

The tumour was myxomatous in character - it had led to a complete fracture of the shaft of the femur just below the trochanter minor (see Fig. 195).

Both this and the tumour of the former patient were examined histologically. The pathologist's report regarding both of them was that evidence of malignant disease could not be found in the parts examined. The comparatively rapid development in each case, and especially the fracture of the femur

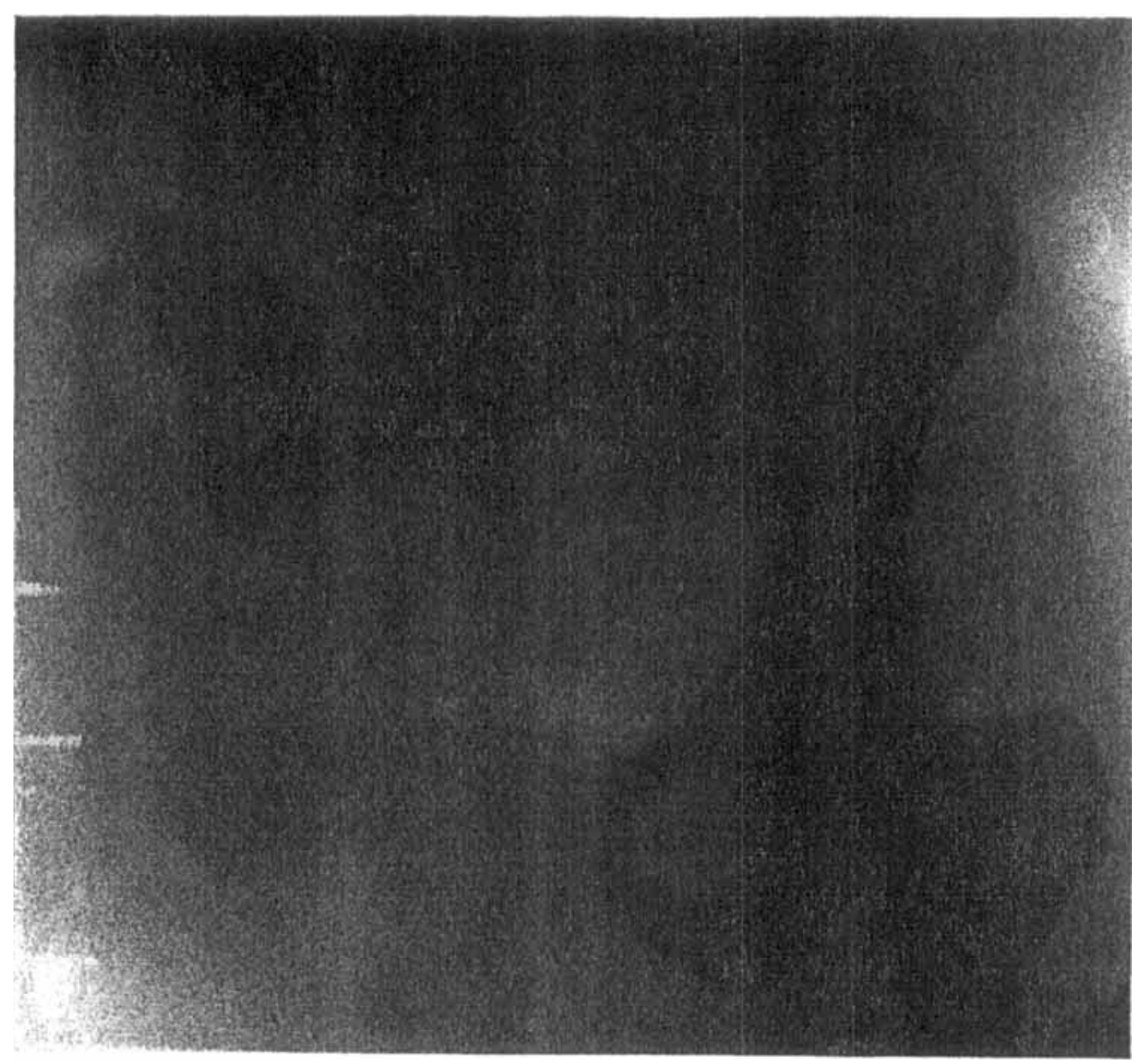

Fra. 194.-Case 4. Sksagram of the pelvis after interpelvi-abdominal amputation of night limb. The ilium was sawn through and the posterior part left.

in the case of Mrs. H., made me think there was no doubt as to the malignant character of the neoplasms.

The points that particularly arise for consideration in connection with this operation are : (1) The prevention of shock ; (2) The flaps to be cut ; (8) The amount of bone to be removed; (4) The control of hæmorrhage.

1. Shock has been the cause of by far the greater number of deaths, and 


\section{THE BRITISH JOURNAL OF SURGERY}

is the chief factor to be reckoned with after the operation. With my three patients operated on for neoplasms I endeavoured to overcome this risk by

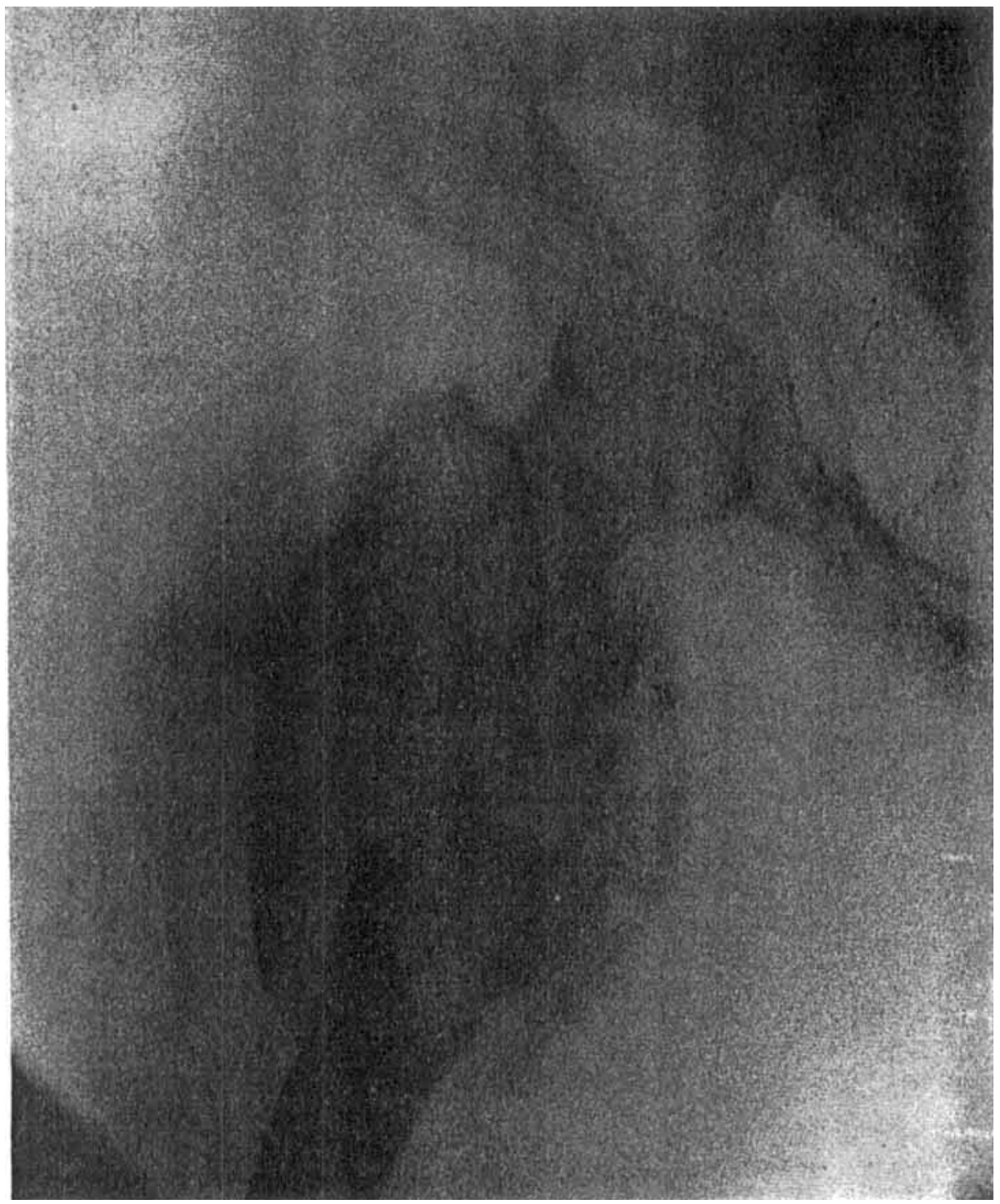

Fia. 195.-Case 5. Skıagram showng tumour of the upper part of the femur, with resulting fracture of the shaft.

(1) The use of scopolamine and morphine beforehand; (2) Spınal anæsthesia (stovaine) ; (3) The infiltration of the large nerve trunks with novocain before they were divided; (4) The intravenous injeetion of saline solution before the 


\section{THE INTERPELVI-ABDOMINAL AMPUTATION 293}

completion of the operation; and (5) Operating upon patients while they were lying upon a warmed table.

Probably each of these factors helped, at any rate the patients survived.

2. The Flaps.-Qute a number of methods of cutting flaps have been employed by the surgeons who have carried out the operation. In some of the cases, owing to the size and position of the tumour, it has been a question of

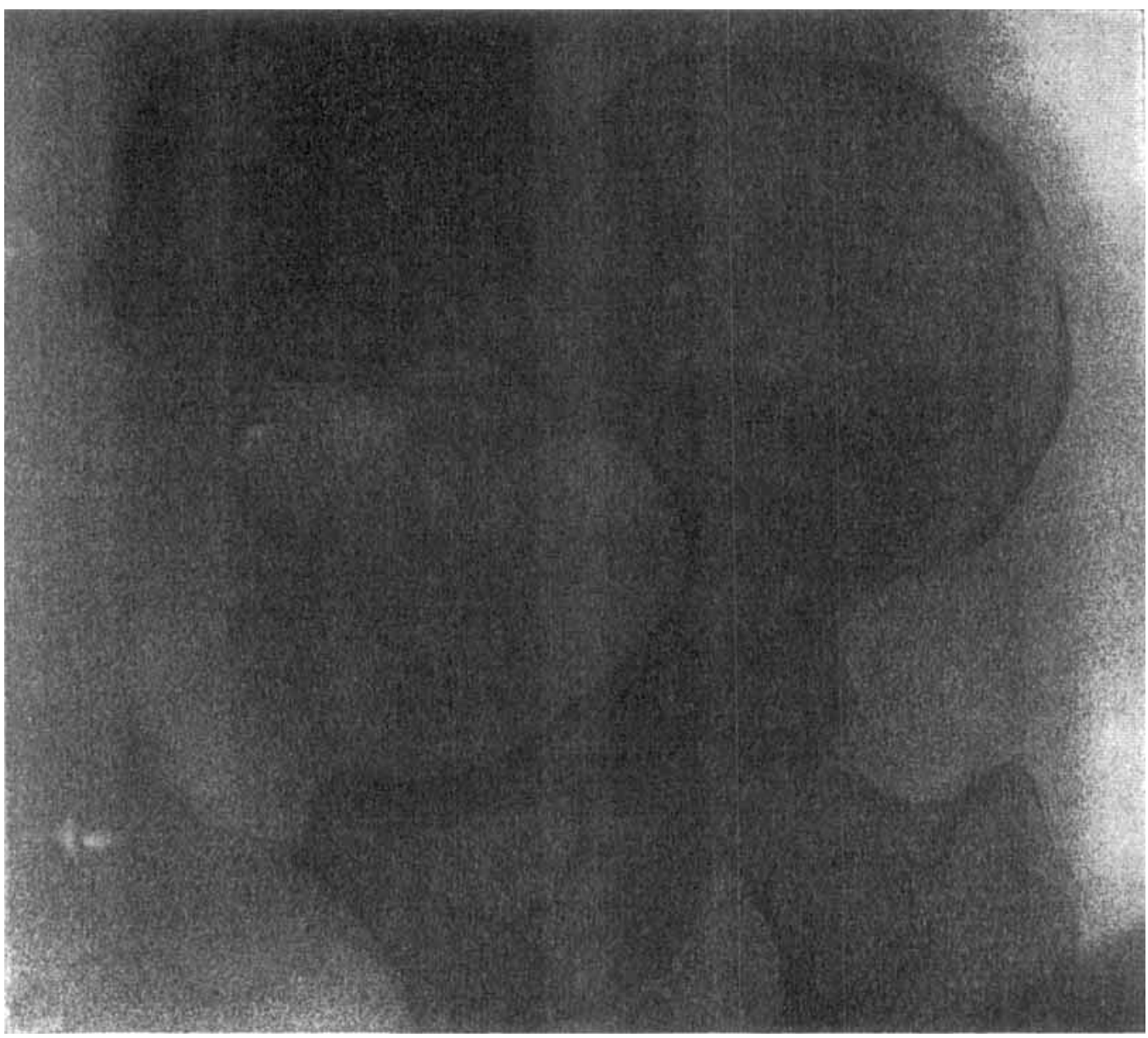

Fio. 196.-Case 5. Skiagram showng the pelvis after interpelvi-abdominal amputation with entire removal of the right hip-bone.

cutting flaps where they could be obtained. I think, where one has the choice of method, that the flaps should be of nearly equal length, and that they will be most advantageously made anteriorly and posteriorly.

In my three neoplasm cases (Cases 3, 4, and 5) I cut flaps that were identical, and which $I$ arrived at from the expenence obtained with the two cases of tuberculous disease (Cases 1 and 2). In each of these I incised along 


\section{THE BRITISH JOURNAL OF SURGERY}

the scar resulting from the exarticulation of the hip, and prolonged the incision up to the crest of the ilium (which was met at about its middle point), and thence along the crest to the posterior superior spine. In Cases 3, 4, and 5, I cut flaps which were, as nearly as possible, similar to these, and they proved to be admirable in each instance. In the two male patients, in whom the ilium was sawn, the flaps were perfectly adapted. In Case 5 (the female patient in whom the ilium was disarticulated from the sacrum) the posterior portion of the wound was just a trifle baggy when the suturing was completed, but the stump is, at this date, quite excellent.

3. The Amount of Bone to be Removed.-Some surgeons have disarticulated at the synchondrosis, and others have sawn the ilium; while anteriorly, in some cases the symphysis has been divided, and in others the pubic rami.

In the case of a neoplasm growing primarily from the ilium, I believe it is essential that the operation should be an exarticulation at the synchondrosis, and possibly in some cases part of the sacrum ought to be removed as well.

Whether the pubic bones ought to be disarticulated from one another at the symphysis, or the ramı of the os pubis divided with the object of preserving the attachment of the rectus abdominis, may in some degree be determined by the site and extent of the tumour, though it will probably always be better to remove the entire os coxæ. Although in Case 3 I preserved the body of the os pubis with the idea of saving the rectus attachment, I do not now think it is necessary to do so, for the result of suturing this and the other muscles of the abdominal wall to the levator ant and to the fascia over the sacrum apparently gives quite adequate support to the abdominal viscera.

In the case of a neoplasm arising in the thigh, the question whether the whole or only part of the hip-bone should be removed must be decided according to the state of things found to exist in any given patient, thus, in Cases 4 and $5, I$ divided the symphysis in front bccause the disease appeared to have invaded some of the muscles taking origin around the obturator foramen ( $F$ igs. 191 and 195), and whereas I sawed the ilium in Case (Fig. 194) because the tumour was placed well away from the gluteal region, in Case 5 , because the tumour seemed to have invaded these tissues (Fig. 195), I disarticulated the ilium from the sacrum (Fig. 196).

From my experience in Cases 3, 4, and 5, I think it requires less time to saw the ilium than to disarticulate, and that disarticulation from the gluteal aspect goes more easily and quickly than from the pelvic side.

4. The Control of Ha:morrhage.-My opinion regarding this point is that all that is necessary to do is to tie or clamp the vessels as one mects them during the progress of the operation.

In Case 3, after shaping the anterior flap, I divided the muscles along the iliac crest, and went directly to the common iliac vessels, whıch I divided between two ligatures, but I wrote in my former paper, that "the advisability of doing this is uncertain should I ever have occasion to do this operation again, I think I would not waste time by exposing the vessels during the early stages of the operation." In the two cases now recorded I put this idea into practice, that is, I clamped with pressure forceps the smaller vessels as they were encountered, and tied the conmon iliac vessels just before they required to be divided. Both patients really lost very little blood, and what blood was lost was due chiefly to oozing from the posterior flap. 
Some of the Continental surgeons responsible for the more recently published cases have greatly lauded the advantage to be gained in this operation by the employment of Momburg's method of controlling the circulation in the lower part of the body I have had a small experience of Momburg's method, having employed it now in ten cases, three being high amputations in the thigh, and seven exarticulations at the hip-joint, and have been highly pleased with it. It affords perfect control of the vessels, and in no single case have I seen any of the inconveniences or disturbances of function that have been attributed to it by some surgeons. In Case 5 there was, after the operation, most troublesome vomiting, and had the Momburg method been employed there is little doubt but that this would have been considered the cause of it. But in spite of my experience of the method, I should not be inclined to use it in a case of the interpelvabdominal amputation, and in the case of a large neoplasm filling the iliac fossa and reaching above the crest, the Momburg method might not be practicable.

Technique.-The procedure I adopted in my last two cases (Cases 4 and 5) was practically the same in each, and was as follows -

The patient was turned slightly on to the sound side, to allow the incision to be commenced at a point just behind the posterior superior spine, whence it ran along the iliac crest to about midway between the two superior spines, and thence to a point in the cruroperineal groove corresponding to the centre of origin of the adductor brevis muscle, the line of incision lying about an inch and a half below the anterior superior spine, Poupart's ligament, and the pubic spine respectively

The anterior flap of skin and subcutaneous fascia was reflected far enough to expose the attachments of the abdominal muscles to the iliac crest and Poupart's ligament, then, beginning at the crest, these muscles were at once cut through, Poupart's ligament was divided at each end, and the rectus abdominis also cut, after drawing the spermatic cord aside (in the female the round ligament was not seen). The deep circumflex iliac and epigastruc vessels were tied close to their origins, and the external iliac artery was clamped just above this point, but the external iliac vem was left free, to allow of as much blood as possible being returned from the limb.

Then, while the limb was well elevated, the posterior flap was marked out, from about the mid-point between the anterior and posterior superior spines down to the gluteal fold, which was followed to meet the inner extremity of the anterior incision in the cruroperineal groove. This flap of skın and fascia was reflected back so far as to expose the ischial tuberosity, in order to obtain room to deal with the perineal structures.

The bladder was next separated from the pubis, and an attempt made to cut through the symphysis. In Case 4 (the male patient) there appeared to be a complete synostosis, and I had to saw the bone, in the female (Case 5) the symphysis was partly cut through, but division had to be completed with a saw Next the genital crus and the tissues of the perineum were separated from the pubic arch. The pelvic organs were well retracted to expose the obturator nerve and vessels, and both this ncrve and the femoral were now injected with novocain solution, the obturator vessels, and then the common iliac artery, were next tied and divided, and the external iliac vein was tied above 
Poupart's ligament, divided, and lifted up from the muscles in the iliac fossa, which were cut just outside the sacro-iliac articulation.

The femoral and obturator nerves were next divided, then the visceral layer of the pelvic fascia and the levator an muscle, the latter being separated back to the ischial spine, and the coccygeus muscle was cut through. The patient was now turned further over on to the side, and the posterior flap reflected to rather beyond the synchondrosis; the gluteus maximus was cut through, and, in the case of the male patient, the ilium was then sawn about an inch outside the sacro-iliac articulation. The roots of the sciatic nerve were now infiltrated with novocain, the larger branches of the hypogastric vessels ligated and divided, and then the piriformis muscle, the roots of the sciatic nerve, and the sacrosciatic ligaments were cut through. In the male patient this set the limb free. In the female, the disarticulation of the ilium from the sacrum, carried out from the pelvic aspect, followed the division of the piriformis and the nerves.

While I proceeded to tie vessels that were held in forceps, my colleague, Mr. John Macintyre, injected about two pints of saline solution through the external iliac vein, which had been kept long specially for that purpose.

Suture of the muscles of the abdominal wall to the fascia over the sacrum, as well as to the levator an muscle and the tissues of the perineum, followed by suture of the skin-a large drain tube being left at the postenor angle of the wound-completed the operation, which lasted fifty-five minutes in the male and about sixty mnutes $m$ the female, the difference being mainly due to the extra time required to disarticulate the synchondrosis in the latter patient.

Both patients were seen in August last, when they were in good health. Both have put on weight. Therr stumps were excellent, without any tendency to hernia formation. In neither of the patients could any evidence of recurrence be detected.

I particularly enquired as to the support afforded by one half of the pelvis while sitting. Both of them stated they were able to sit upon a hard chair without any discomfort until an attempt was made to lean over towards the operated side, when they lost their balance. They are able to overcome this disability entirely by the use of a cushion beneath the stump.

When my first three cases were recorded in 1909, up to which time I had been able to collect twenty-one additional cases, there was a total mortality of 75 per cent ; or. takıng the cases of neoplasms alone, a mortality of 67 per cent in the nineteen cases known. If one compares these results with those of the cases known to have been operated up to the present tıme, it will be seen that a great improvement has taken place; over the total forty-three cases there is a mortality of 58.1 per cent ; or, taking the cases of neoplasms alone. a mortality of $56 \cdot 6$ per cent, a very remarkable reduction.

There has scarcely been a single operation of any magnitude that has not in the early stages of its development been looked at askance, and the interpelvi-abdominal amputation must always remain one of the severest in surgery. But. If the real nature of these cases be recognized at an early stage, and the operation can be carried through before the patients have commenced to run down in consequence of the disease, the mortality following it will, I believe, be so far diminished that justification of the operation will in the future be generally admitted. 